\title{
The Gardner hypothesis
}

\author{
The scientific jury is still out
}

"The editorial is a contrick-usually a personal view written by an English eccentric." Thus spoke Stephen Lock, former editor of the $B M \mathcal{A}$, at a meeting last month commemorating the work of the late Martin Gardner. The meeting, organised by the $B M F$, focused on Gardner's work, including his great contribution to raising the standards of papers in medical journals. The challenge now, Lock argued, is similarly to raise the standard of editorials. Writing an editorial about the meeting is thus doubly difficult.

The memorial meeting also addressed Professor Gardner's extensive work on occupational carcinogenesis and environmental hazards and the teaching of medical statistics. But he is best known for the hypothesis that now bears his name. This was derived from a large, detailed study conducted to examine the 10-fold excess of childhood leukaemias identified in the village of Seascale near the Sellafield nuclear plant. ${ }^{1}$ It postulates that fathers' occupational exposure to ionising radiation before conception increases the risk of childhood leukaemia. The original study formed the basis of a lengthy court case against British Nuclear Fuels plc (BNFL), during which it received extensive scrutiny. The judgment in early October in favour of BNFL provoked much media interest.

New studies examining the hypothesis have recently been published, amid further publicity. ${ }^{2-4}$ Timed to coincide with the memorial meeting for Gardner, a book was published containing the main research articles of the past decade that have addressed the problem of clusters of leukaemia near nuclear plants. ${ }^{5}$ In view of the recent publicity, the meeting itself was a timely opportunity to discuss the scientific issues. This editorial is a "personal view" of the Gardner hypothesis and the discussion of it at the meeting.

When the striking findings of the case-control study by Gardner et al were published in 1990 they broke new ground. Here was a possible explanation of the excess of leukaemias in Seascale. In the study, preconceptional exposures of the fathers of 46 cases of leukaemia, born in west Cumbria and diagnosed there between 1950 and 1985, were compared with those of 564 controls. An association was found between the exposure and leukaemia, but this was dominated by four case fathers with high exposure ( $>100 \mathrm{mSv}$ ). Thus the hypothesis was based on small numbers. But, for the first time since the cluster was identified in 1983, here was a hypothesis that could be tested.

Nearly four years later, the results of further research are available. Two case-control studies have examined the clusters of leukaemia near Dounreay and Aldermaston and
Burghfield.$^{67}$ Only one father (of a control rather than a case) in the two studies had been exposed to radiation of more than $100 \mathrm{mSv}$, and paternal preconceptional irradiation therefore cannot explain the excesses of leukaemia near these nuclear sites. Nor in fact can it explain the entire excess in Seascale, as children of unexposed fathers also have increased rates of the disease. ${ }^{8}$ Two large case-control studies ${ }^{39}$ comprising over 1000 cases in Scotland and Canada have failed to confirm the association seen in the Gardner study. Only eight of the fathers in the two studies had been exposed to more than $100 \mathrm{mSv}$, although none of them was the father of a case. With such small numbers, the negative results cannot completely refute the Gardner hypothesis, though they do not support it. Parker et al have shown that the children born outside Seascale to workers exposed to preconceptional irradiation do not have an increased risk of leukaemia, ${ }^{2}$ and a recent report from the Health and Safety Executive has confirmed this for outside Seascale. ${ }^{4}$ The report, however, replicates Gardner's findings for those born in Seascale whose fathers started work at Sellafield before 1965 .

Although little support now exists for a direct causal relation, the association between paternal preconceptional irradiation and leukaemia observed in Seascale remains unexplained. Gardner himself suggested that some other paternal exposure (for which to date there are few clues), such as to chemicals or internal exposure to radionuclides, might be responsible. For this to be so, measured external irradiation would have to be a marker in the Seascale fathers.

Other explanations for the Seascale cluster have focused on infectious agents, so far unidentified. The large influx of people to Seascale when the nuclear plant was built could have led to shifts in the pattern of exposure to infectious agents, which in turn could have given rise to an increased risk of leukaemia. Studies of new towns ${ }^{1011}$ and the population changes due to expansion of the oil industry in Scotland ${ }^{12}$ show that excesses of leukaemia have been observed in the first few years after large population movement, though mainly in those under 5 years of age. The excess in Seascale is also apparent in older age groups and has occurred over 40 years. Thus population mixing does not appear to provide a complete explanation for the cluster.

A decade after its identification we are still unclear as to why the cluster at Seascale is there. The excess of childhood cancer has continued, but there has been a shift in the diagnostic pattern towards non-Hodgkin's lymphoma and other cancers, mainly in older children. ${ }^{13}$ The cases in the village have 
occurred over a long period and are a disparate group of different diagnoses. The Sellafield plant has probably been at least partly responsible, either directly, such as through preconceptional exposures, or indirectly if population mixing is a cause. The judge decided on the balance of probabilities that paternal preconceptional irradiation did not cause the two cases brought to the court. In the scientific community, preconceptional exposures are still being investigated and the jury is still out. The Gardner and infectious agent hypotheses need further work, but other factors may also be operating. Martin Gardner provoked researchers into a new field of investigation. Such challenges to the scientific community are few and far between, and more are needed if the causes of leukaemia and lymphoma are to be identified.

HAZEL INSKIP

1 Gardner MJ, Snee MP, Hall AJ, Powell CA, Downes S, Terrell JD. Results of case-control study of leukaemia and lymphoma among young people near Sellafield nuclear plant in west Cumbria. $B M 7$ 1990;300:423-9.

2 Parker L, Craft AW, Smith J, Dickinson H, Wakeford R, Binks K, et al. Geographical distribution of preconceptional radiation doses to fathers employed at the Sellafield nuclear installation, west Cumbria $B M 7$ 1993;307:966-71.

3 McLaughlin JR, King WD, Anderson TW, Clarke AE, Ashmore JP. Paternal radiation exposure and leukaemia in offspring: the Ontario case-control study. $B M Y 1$ 1993;307:959-66.

4 Health and Safety Executive. HSE investigation of leukaemia and other cancers in the children of male workers at Sellafield. Sudbury: HSE Books, 1993.

5 Beral V, Roman E, Bobrow M, eds. Childhood cancer and nuclear installations. London: BMJ Publishing Group, 1993.

6 Urquhart JD, Black RJ, Muirhead MJ, Sharp L, Maxwell M, Eden OB, et al. Case-control study of leukaemia and non-Hodgkin's lymphoma in children in Caithness near the Dounreay nuclear installation. BMF 1991;302:687-92. (Reproduced in reference 5.)

7 Roman E, Watson A, Beral V, Buckle S, Bull D, Baker K, et al. Case-control study of leukaemia and non-Hodgkin's lymphoma among children aged 0-4 years living in west Berkshire and north Hampshire health districts. BMF 1993;306:615-21. (Reproduced in reference 5.)

8 Kinlen LJ. Can paternal preconceptional radiation account for the increase in leukaemia and nonHodgkin's lymphoma in Seascale? BMF 1993;306:1718-21.

Kinlen $L$, Clarke $K$ Balkwill A. Paternal preconceptional radiation exposure in the nucles industry and leukaemia and non-Hodgkin's lymphoma in young people in Scotland. $B M \mathcal{J}$ 1993;306:1153-8. (Reproduced in reference 5.)

10 Kinlen L. Evidence for an infective cause of childhood leukaemia: comparison of a Scottish new town with nuclear reprocessing sites in Britain. Lancet 1988;ii:1323-7. (Reproduced in reference 5.)

11 Kinlen LJ, Clarke K, Hudson C. Evidence from population mixing in British new towns 1946-85 of an infective basis for childhood leukaemia. Lancet 1990;336:577-82.

2 Kinlen LJ, O'Brien F, Clarke K, Balkwill A, Matthews F. Rural population mixing and childhood leukaemia: effects of the North Sea oil industry in Scotland, including the area near Dounreay nuclear site. $B M \mp$ 1993;306:743-8. (Reproduced in reference 5.)

3 Draper GJ, Stiller CA, Cartwright RA, Craft AW, Vincent TJ. Cancer in Cumbria and in the vicinity of the Sellafield nuclear installation, 1963-90. BMf 1993;306:89-94. (Reproduced in reference 5.)

\section{General practitioners and incentives}

\section{Carrots and sticks may make GPs behave more like donkeys than doctors}

Incentives probably influence the activity of some general practitioners all of the time and all general practitioners some of the time. But no incentive package yet offered influences all general practitioners all of the time.

This is unsurprising as the general practice workforce is not a homogeneous group in terms of skills, commitment to whole population perspectives, and attitudes to scientific medicine. The growth of practice teams-itself a consequence of successive incentives for multidisciplinary working-may make responses to incentives even more variable, simply because of the greater variety of players in the game.

General practitioners' responsiveness has prompted some analysts to propose that management interventions are needed to deal with family doctors who fail to respond "rationally" to economic incentives." Others regard the development of teams working from purpose designed premises in $40 \%$ of practices, over one decade, as evidence of a strong response to incentives. ${ }^{2}$ Both viewpoints have found expression in the 1990 contract, but the belief in incentives has gained greater weight.

Although effective incentives need not be material, they often are. Bosanquet and Leese showed that the development of primary care teams in general practice between 1977 and 1987 could be attributed primarily to a combination of demand pressures (population growth) and supply opportunities (cheap labour and available sites for new premises). ${ }^{3}$ Local professional leadership also promoted growth but was a secondary factor, operating most powerfully in poorer areas.

The material incentives for general practitioners introduced in 1966 were relatively simple, with fees for items of service increasing the provision of cervical cytology screening and contraceptive services in general practice. But these were not accompanied by appreciable uptake of smear tests by those women with the highest risk or by any fall in the rate of unplanned pregnancy and abortion. Subsidies for premises and staff introduced in the family doctors' charter of 1966 prompted only limited development until the late $1970 \mathrm{~s}^{3}$ even though the subsidies for premises effectively created a second pension for enterprising and innovative doctors.
More recently, economic incentives have become more complex, with a mixture of positive and negative incentives in the same package. For example, targets for immunisation of children and for cervical smear testing have been achieved faster than expected, not only because of target payments but also because practice incomes were threatened by the reduction in the basic practice allowance and the increased emphasis on capitation introduced in 1990. When fees for items of service have been extended, as in minor surgery, a ceiling has been added to prevent an epidemic of claims. Health promotion and activities for managing chronic diseases have also become subject to increasingly complex incentives, with as yet unknown consequences for public health.

In one sense general practice fundholding is itself an elaborate form of economic incentive, creating the possibility for reallocation of resources within the practice, including the development of improved premises that will yield, in time, improved extra pensions for their owners. One immediate effect of this incentive has been the curbing of increases in prescribing costs that has occurred in fundholding practices. ${ }^{45}$ This refutes earlier speculation that increased list sizes would mean shorter consultations, less attention to psychosocial factors, and therefore more prescribing ${ }^{6}$ and strengthens the argument for complex packages of incentives.

These complex incentives seem to be powerful, but do they raise the health status of the population as much as they do the income of the practice? Incentives may have the perverse effect of increasing inequalities in health care, either through the unequal provision of services or through their unequal uptake. Singlehanded practices responded less than larger practices to the incentives to run health promotion clinics, yet the areas that these practices serve often need disease prevention most. Because achieving even a 50\% target for cervical smear testing is regarded as unrealistic in some inner city areas some general practitioners are tempted to abandon any attempt at screening. Even if incentives can be designed that overcome this perversity people also respond in different ways to inducements to improve their health, so that inequalities in the uptake of cervical smear tests and other 